\title{
Public opinion in policy contexts. A comparative analysis of domestic energy policies and individual policy preferences in Europe
}

\author{
Isabelle Stadelmann-Steffen \\ University Bern \\ Institute of Political Science \\ Fabrikstrasse 8 \\ 3012 Bern, Switzerland \\ isabelle.stadelmann@ipw.unibe.ch \\ Christina Eder \\ GESIS - Leibniz Institute for the Social Sciences \\ Postbox 122155 \\ 69072 Mannheim, Germany \\ christina.eder@gesis.org
}

Accepted version of the article published in the International Political Science Review, https://doi.org/10.1177/0192512120913047

\begin{abstract}
Recent research and real-world processes emphasize that effective climate change mitigation policies are not feasible without at least a certain degree of public support. Hence, we investigate the link between existing domestic energy policies and individual policy instrument preferences in 21 European countries. We assume a policy feedback perspective and depart from the idea that the current domestic energy context influences what future policies are possible and preferred by citizens. High political trust and strong climate change attitudes are expected to strengthen this relationship. Our results do not lend support to a general link between existing policies and future policy preferences. However, we find evidence of a positive policy feedback in individuals with strong climate change attitudes and/or high levels of political trust, which, depending on each country's current energy policy, either hinders or facilitates the energy transition.
\end{abstract}

Key words: environmental policy, political attitudes, energy policy, policy preferences 


\section{Introduction}

The Paris Agreement saw almost all countries in the world agree to fight climate change and keep global warming well below the $2{ }^{\circ} \mathrm{C}$ threshold. Even though the treaty was celebrated as a great success, it would amount to nothing more than hollow words unless followed by serious action. Thus, governments and parliaments need to adopt new policies or adapt existing ones to trigger the necessary changes in their countries (see Le Quéré et al. 2019). Such policies could range from taxes on greenhouse gas emissions or bans on coal-fired power plants to subsidies for public transport and educational programs in schools. The variety of possible policies reflects the complex challenge posed by the changing climate. Global warming has several causes and many effects, such as melting polar ice and glaciers, rising sea levels, extreme weather events, changes to flora and fauna; and these effects might affect different places in quite different ways. Consequently, states have chosen very different approaches to protecting their environment, with some even deciding against taking any action (Schmidt and Fleig, 2018).

Policy making in democracies is a complex process involving many actors: politicians and parties, lobbyists, experts and NGOs, all with their own position on issues. There are also voters, who evaluate the performance of governments at election time if not before. Therefore, both recent research and real-world experience suggest that the (sometimes dramatic) policy changes necessary to mitigate climate change require at least a certain degree of public support (Edenhofer et al., 2012: 129). Indeed, lack of social acceptance by citizens may be one important factor - besides, for example, institutional aspects (Peters et al. 2017) and an absence of elite consensus (see Carter and Little in this issue) - leading to politicians' underwhelming reactions to climate change (Dermont et al. 2017).

We argue that the link between the domestic policy context and individual policy preferences is crucial and deserves detailed investigation. The present study therefore assumes a policy feedback perspective and departs from the idea that the current domestic energy context influences what future policies citizens can imagine and prefer. Previous work focusing on single countries has demonstrated that citizens' opinions depend on policy design, particularly on personal cost-benefit considerations, with the current policies serving as an important reference category (Shwom et al., 2010). Here, we investigate the role of the domestic energy sector in shaping citizens' support for or resistance to policy change. Moreover, we consider that policy feedback will be contingent on individual attitudes toward both climate change and 
domestic politics. At the individual level, acknowledging the need to act on anthropogenic climate change is an important precondition for supporting renewable energy and climate change mitigation policies (Ziegler, 2017). At the national level, since governments play a pivotal role in setting the political debate, political trust presumably moderates citizens' readiness to accept new policies (cf. Harring, 2014). When new policies deviate (strongly) from the status quo, trust in governments, politicians and parties-that is, the perception that these people are trustworthy and do the 'right thing'-may compensate for the uncertainty these policies involve.

We explore these questions using data on energy and the environment from the European Social Survey 2016's module ${ }^{1}$, including items on energy policy preferences and attitudes towards climate change. To measure the domestic energy context, we collected country-level data on states' current energy mix and existing policies. Multilevel models enable us to parse out the relationship between contextual and individual level variables and policy instrument preferences.

Our results do not support the view that the starting energy policy context affects individual policy preferences more broadly. However, we do find support for a positive policy feedback in individuals with strong climate change attitudes and/or high levels of political trust. On the one hand, this means that a renewable energy policy can reinforce itself by increasing these individuals' readiness to take further action. On the other hand, however, the mechanisms to follow a chosen path are also relevant in a fossil energy context: where fossil energy is (economically) important, even individuals with high levels of political trust and/or strong climate beliefs are more reluctant to support specific renewable energy policies.

The remainder of the chapter is structured as follows. The next section is dedicated to reviewing previous research on public preferences and public policy and outlines our theoretical background and the hypotheses we test for. We discuss our empirical approach in section 3 , before presenting our results in section 4 . The article concludes with a discussion of our main findings and their implications.

\footnotetext{
${ }^{1}$ ESS Round 8: European Social Survey Round 8 Data (2016). Data file edition 2.1. NSD - Norwegian Centre for Research Data, Norway - Data Archive and distributor of ESS data for ESS ERIC. doi:10.21338/NSD-ESS8-2016.
} 


\section{Theoretical background}

Linking domestic energy policies and individual policy preferences places us in the rich literature on public opinion and public policy in general (cf. Wlezien and Soroka, 2016), as well as the 'green policy' realm in particular (cf. Cherry et al., 2014; Dermont, 2018; Drews and van den Bergh, 2016; Engels et al., 2013; Harring and Jagers, 2013). We thus build on recent work arguing that, "[I]n representative democracies, for policy measures to be adequately and effectively implemented, or even be decided on at all, public support is essential" (Jagers et al., 2018: 89). A lack of social acceptance by citizens has been identified as one of the main hurdles to energy transitions (Dermont et al. 2017), and can, thus, be seen as an important explanation for countries' under-reactions in terms of climate policy (Peters et al. 2017).

The factors influencing the acceptance of renewable energy and climate change policies have been subject to significant scholarly attention (Aasen and Vatn, 2018; Drews and van den Bergh, 2016; Harring, 2014; Harring and Jagers, 2018; Jagers et al., 2018; Shwom et al., 2010; Wolsko et al., 2016). Here, we go further by focusing on how existing policies affect support for new policies. The idea that "policies, once enacted, restructure subsequent political processes" (Skocpol, 1992: 58) is the core of the policy feedback approach. In this perspective, policies may transform both structural factors, like state capacities and administrative arrangements, and the attitudes and behaviors of specific groups or entire populations (Kumlin and Stadelmann-Steffen, 2014). Thus, applied to our research question, the policy feedback approach suggests that individual preferences for renewable energy policies will be contingent on the current domestic policy context. However, feedback processes may be complex and involve both positive and negative feedback effects. Based on existing studies, we can derive different mechanisms through which the status quo could influence individual preferences for new policies.

One perspective, heavily influenced by the work of Wlezien (1995), suggests that the public can be understood as a "thermostat." In this view, public attitudes, opinions and preferences serve as a guideline for politicians' decision-making. How well this thermostat works is then conditional on the respective policy field and preconditions, such as accuracy and information availability. This thermostatic view also implies a potential for negative feedback effects: At some point, the public may think that enough has been done in a field and reject further policy change. Soroka and Wlezien's (2009) extensive study on the development of individual spending preferences in the US, Canada and UK, where they show that an increase in welfare 
state spending in one year led to a decrease in individual spending preferences in the following year, supports this expectation.

The cost structure in the climate and energy policy sector means that such negative feedback may be especially relevant. In particular, ecological taxes and subsidies contain inherent costs (Stadelmann-Steffen and Dermont, 2018), which tend to be highly visible (Stokes, 2013: 49). Thus, whereas individuals may accept some subsidies and moderate taxes to support energy transitions, they may be reluctant to see further expansions of these instruments. Stokes (2013) shows how these negative feedback mechanisms worked in the case of Ontario's feed-in tariff policies: while the introduction of the instruments was not very conflictive, opposition based on the costs that they entailed grew with and after their implementation. In keeping with this account, we derive our first hypothesis:

H1: The more extensive the renewable energy policies a country exhibits, the lower the individual preferences for taking further measures are. ${ }^{2}$

In contrast, a second perspective envisions a positive feedback between existing policies and preferences for new policies. This is the classic argument of the "new politics of the welfare state" literature (Pierson, 2011): if people get used to something, they want to keep it. It maintains that the welfare state has been creating its own constituency, which most obviously consists of those who profit from a certain policy. Nevertheless, the feedback effects can be much broader, since policies support and generate specific norms and identities (Kumlin and Stadelmann-Steffen, 2014).

Research on the public's acceptance of renewable energy also provides evidence for a positive feedback effect. For example, several studies on renewable energy infrastructure have demonstrated that opposition towards wind parks or high voltage lines decreased with real-life experience (cf. Firestone et al., 2012; Stadelmann-Steffen, 2019). Stokes (2013: 497) argues that subsidies for renewable energies in particular "have the potential for path dependence through reinforcing coalitions." Building on this strand of literature, and in contrast to H1, we formulate a second hypothesis:

\footnotetext{
${ }^{2}$ Whereas the thermostat argument inherently involves a dynamic element, for which we cannot test with our cross-sectional design, we argue that a negative correlation between the share of renewables and individual preferences for taking further measures can nevertheless be seen as an indication of a (dynamic) thermostatic feedback. This is because a high share of renewables today is the result of past political decisions, which influence today's preferences.
} 
H2: The more extensive the renewable energy policies a country exhibits, the stronger the individual preferences for taking further measures are.

However, Soss and Schram (2007) reason that the way existing policies inform individual attitudes and preferences depends on proximity and visibility. The proximity dimension concerns the degree to which individuals have gained experiences with a particular policy, whereas the visibility dimension is related to the idea in political behavior research that an issue influences public opinion only if it is visible and salient. We argue that proximity and visibility may be a function of individual attitudes. Energy policy is a rather distant issue for many people: energy literacy (Brounen et al., 2013) and knowledge of the functioning of energy policies (Stadelmann-Steffen and Dermont, 2018) have been shown to be rather low. ${ }^{3}$ Moreover, the energy issue often commands a lower priority than more salient issues (Lowry and Joslyn, 2014) like migration or unemployment. ${ }^{4}$ Yet, for some groups, energy policy may be highly visible and proximate, which should strengthen the link between existing policies and these individuals' policy preferences.

Most obviously, the energy policy context will be more proximate and salient for individuals with strong climate change attitudes. Climate change concern and environmental attitudes are an important prerequisite for forming an opinion on environmental public policy: while climate change acceptance and concern for the environment are linked to greater support for green policies, climate change skepticism or denial reduces support for political action in this realm (Engels et al., 2013: 1024f.). In the US, in particular, "political affiliation is one of the most consistent predictors of a range of environmental attitudes and support for environmental policy (...) political conservatives or self-described Republicans are less concerned about environmental issues, less supportive of environmental policy and less likely to engage in individual environmental behaviors" (Mayer and Smith, 2017: 74). In European countries with multi-party systems, the effect of party affiliation is less pronounced, especially where all the major parties accept anthropogenic climate change and the need to mitigate its effects. ${ }^{5}$

\footnotetext{
${ }^{3}$ We generally expect that most people will not be aware of their country's exact energy mix and even less aware of specific energy policies. However, while such specific knowledge is not necessary for a feedback effect to exist, more prominent issues, such as coal phase-out, energy transition, and renewable energy infrastructure, have arguably been important matters in the public discourse in almost all European countries and at the EU-level. Hence, most people will have a sense of the general lines of the discussion. Nevertheless, we argue that individuals will vary in their interest and sophistication regarding energy policy.

${ }^{4}$ This assumption is particularly reasonable in view of our data, which were collected in 2016 at the height of the so called "European migration crisis."

${ }^{5}$ This does not imply that all the parties favour identical solutions to the problem; quite the contrary. But they all acknowledge the existence of global warming and the need to take action. Accordingly, McCright et al. (2016:
} 
Consequently, Ziegler (2017: 149) does not find political orientation to be "relevant for differences in general climate change beliefs in Germany." However, acknowledging the need to take measures against anthropogenic climate change is vital for backing renewable energy and climate change mitigation policies (Ziegler, 2017: 144).

What do these considerations entail for potential feedback effects? The thermostatic perspective would expect individuals with strong climate change attitudes and climate change skeptics to show different saturation points. While the latter would immediately "have enough" of renewable energy policies, the former would experience the aforementioned negative feedback mechanisms much later (if at all). Moreover, positive feedback effects are more likely in the case of the former: given that renewable energy policies are in accordance with their beliefs, they are more likely to evaluate such policies positively and to internalize the norms they convey. As a result, a reinforcing effect of accepting more far-reaching policies is most probable. We thus formulate our third hypothesis:

H3: Compared to climate change skeptics, individuals with strong climate change attitudes will exhibit a stronger positive feedback and a weaker negative feedback in their support for renewable energy policies.

Political trust is another important factor singled out by previous research. Trust is found to be directly associated with individual willingness to comply with existing rules and laws and with the acceptance of government policies in general: when political trust is low, defections are said to become more likely, policies are harder to implement, and government support dissipates (cf. Citrin and Stoker, 2018; Hetherington, 2014). Furthermore, climate change is a crossnational collective action problem that needs a certain level of political and social trust to reduce the risks of free-riding (Harring and Jagers, 2013) and failure to act. Other researchers highlight the importance of corruption for the implementation of environmental policies (Fredriksson and Neumayer, 2016; Harring, 2014). Based on these insights, we formulate our fourth and final hypothesis:

H4: Compared to individuals with low political trust, individuals with high political trust will exhibit a stronger positive feedback and a weaker negative feedback in their support for renewable energy policies.

350) report a "robust, modestly sized left-right divide on climate change views in the general publics of Western European countries." 


\section{Data, variables and research design}

As we strive to link individual preferences to domestic policies, we need information on the micro-level: mainly on citizens' policy preferences, their attitudes towards climate change, and levels of political trust, but also on the macro-level - on the policies in place. The following paragraphs first outline the individual-level information we work with and then turn to some contextual factors, in particular, the domestic energy policies in place.

\subsection{Individual preferences}

For the purpose of assessing individual attitudes, norms, beliefs, and preferences, we make use of the $8^{\text {th }}$ round of the European Social Survey. This survey was conducted in 2016 and 2017 in $21 \mathrm{EU}$ and EFTA countries and contains, among others, a module on climate change comprised of more than 30 items. The dataset is the most comprehensive one currently available, and allows for testing our hypotheses cross-nationally with the most recent data.

Accordingly, almost $93 \%$ of all survey respondents indicated that the world's climate is definitely or probably changing. About $47 \%$ are somewhat worried about climate change, while another almost $29 \%$ are very or extremely worried. When asked to what extent they feel a personal responsibility to reduce climate change, close to $60 \%$ place themselves in values between 6 and 10 (a great deal) on an 11-point scale. Roughly 16\% choose the middle category. If it comes to changing one's own behavior, results are far less clear. Asked how likely they are to limit their own energy use to reduce climate change, a mere $39 \%$ answered with values between 6 and 10 (extremely likely) with less than 5\% picking 9 or 10 . Nearly $50 \%$ indicated a rather low readiness to reduce their personal energy consumption. In sum, European citizens know that climate change is happening, more than $2 / 3 \mathrm{rds}$ are worried about it, and a majority accepts an individual responsibility for preventing it. Yet, we find large cross-country variation as, for instance, almost $78 \%$ of Swiss citizens indicate an individual responsibility, while only $27 \%$ of Czechs do, too. These differences are also reflected in individuals' readiness to reduce their own energy consumption. In Czechia and Estonia, 58\% and 63\% would not reduce their own energy consumption, while in Lithuania, $50 \%$ would be ready to do so.

In terms of policy preferences, Figure 1 illustrates substantial cross-country differences in the extent to which individuals agree on an increased tax on fossil fuels, subsidies for renewable energy production, and a ban on the sale of the least energy-efficient household appliances, respectively. For example, whereas a majority supports such tax increases in Sweden and 
Finland, in Poland, Italy, Ireland, France, and Spain over 50\% of all respondents oppose increasing the tax on fossil fuels. In addition, we find systematic variance in support for the three policy instruments. Subsidies and bans are clearly more popular, while the tax on fossil fuels provokes the greatest opposition. ${ }^{6}$

\section{Figure 1: Preferences towards renewable energy policies in European countries}
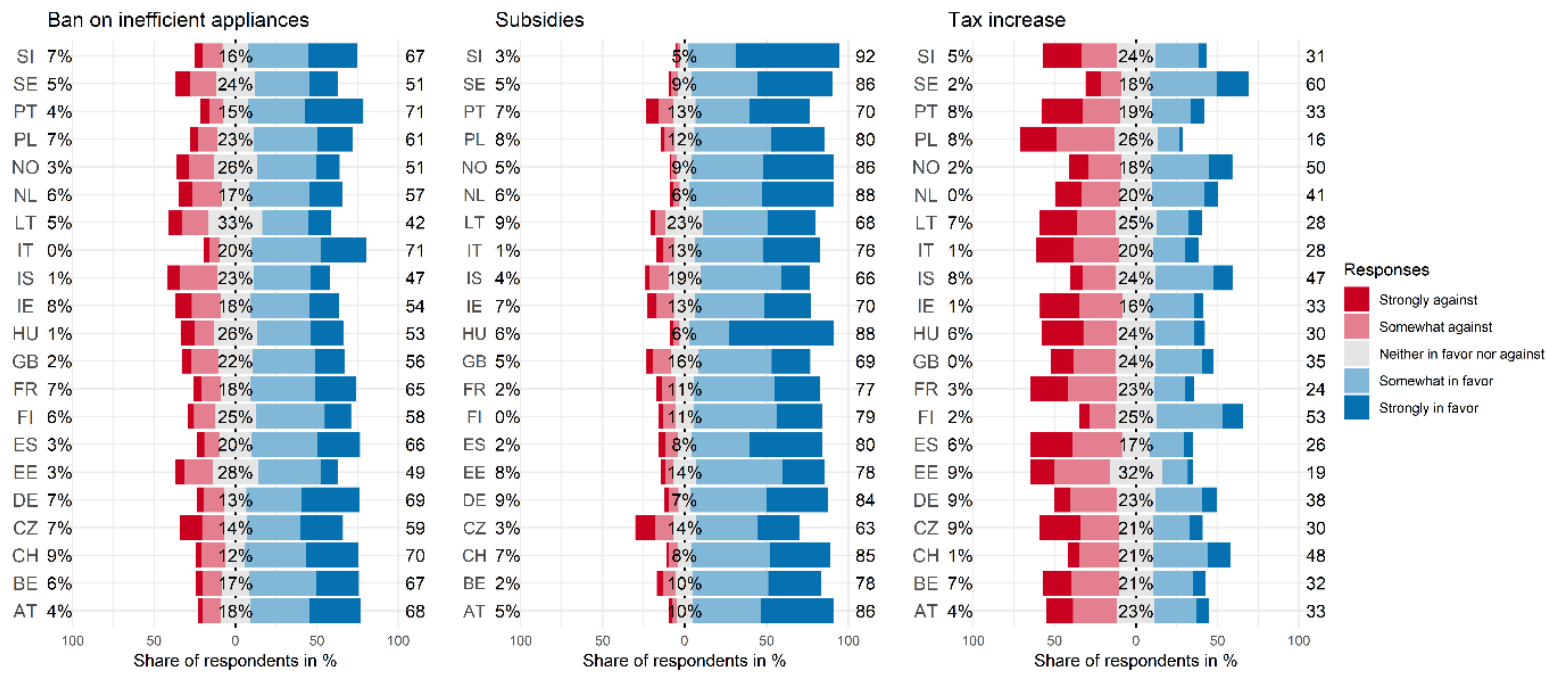

Note: Preferences towards renewable energy policies, unweighted shares.

\subsection{Domestic energy policy}

Domestic energy policies comprise a diverse field, so we concentrate on two aspects that we expect to be closest to citizens' experiences: the existing energy policies and current energy mix. Policies designed to mitigate climate change typically concern the use or production of energy; they aim at reducing energy consumption and producing more energy from renewable sources and less from fossil sources. Comparative data on which instruments states actually choose to reach their climate targets are scarce. We use data collected and provided by Schmidt and Fleig (2018), who have coded the Climate Change Laws of the World database ${ }^{7}$ for each country and category and over time. These data capture whether and when countries have introduced regulations in different policy areas. We focus on the areas that are conceptually and theoretically related to the three individual-level dependent variables: carbon pricing, energy demand, and energy supply. The data do not inform about the content of these policies, such as

\footnotetext{
${ }^{6}$ Although these differences are in keeping with previous research (cf. Carattini et al., 2017; Ingold et al., 2018; Stadelmann-Steffen and Dermont, 2018), we would like to point out that the tax-related question seems to be formulated in the most concrete way in the ESS (i.e., an increase in a tax on fossil fuel), which may cause the comparatively higher rejection rates.

${ }^{7}$ Compiled by the Grantham Research Institute on Climate Change and the Environment in collaboration with the Sabin Center for Climate Change Law: www.lse.ac.uk/GranthamInstitute/climate-change-laws-of-the-world.
} 
the policy instruments they contain. This is one reason why variance on some relevant measures is limited in our sample of European countries. ${ }^{8}$

The dataset does show some cross-national variance in carbon pricing. Fifteen countries have regulations in this field, while the rest do not. According to Schmidt and Fleig (2018), policies concerning carbon pricing rank among the least developed policy categories and exhibit the lowest growth. This unpopularity corroborates earlier research on ecological taxes (cf. Carattini et al., 2017; Stadelmann-Steffen and Dermont, 2018). In light of the structural difficulty of implementing such policies, the presence of carbon pricing is interpreted as these countries having taken a step towards an effective climate policy that other countries have so far failed to realize.

In contrast, all countries of interest have set regulations in the realms of energy supply and energy demand. However, countries vary quite considerably in when they implemented these policies. Whereas Norway has been a forerunner in that it introduced energy demand policies as early as 1976 and energy supply stipulations in 1990, Hungary, Lithuania, and Portugal have only followed after 2005. We argue that these time lags are indicators of a country's energy policy history, which-as specified in our hypothesis-may influence citizens' policy preferences even today. Given that the correlation between the time when regulations on energy demand and energy supply were first introduced is high $(0.63, \mathrm{p}<0.05)$, we focus on a single variable, i.e., energy supply.

The second dimension of the domestic energy policy is a country's current energy mix. Arguably, while citizens can find energy policies rather abstract and complex, the energy sources a country relies on are more visible and tangible. We therefore have compiled data on the countries' energy sources from the World Bank's databases. ${ }^{9}$ We consider the share of electricity produced from fossil energy by presenting the electricity production from coal and oil as a percentage of the total electricity production. Moreover, we sum electricity production from hydropower and renewables to measure a country's share of renewable energy. ${ }^{10}$

\footnotetext{
${ }^{8}$ This also concerns data from other sources. For example, Tosun (2018) provides data on when countries have introduced renewable energy targets. Most countries introduced such targets in 2010, with Iceland and Switzerland introducing them slightly earlier, and Portugal and France only defining them in 2015.

${ }^{9}$ https://data.worldbank.org/indicator/EG.ELC.FOSL.ZS?view=chart (last visited on 13 March, 2019).

${ }^{10}$ We refrain from integrating nuclear energy, mainly because different countries display different arguments and views about whether this source is a way to meet $\mathrm{CO}_{2}$ targets or a source that should be replaced, just as fossil energy.
} 


\subsection{Research design}

To test our hypotheses, we estimate hierarchical linear models and account for group-specific relationships, such as varying policy effects contingent on individual trust and climate change attitudes, by including cross-level interactions. In addition to the main explanatory variables, we also include a series of individual-level variables based on previous research (e.g., Ingold et al. 2018; Stadelmann-Steffen and Dermont 2018). Information on coding and descriptive statistics of all included variables can be found in Table A.1 of the online appendix.

Since our dependent variables are measured on 5-point Likert scales and are ordinal, we also run ordered logistic regressions. Given that these estimations do not lead to different results and because ordered logistic regressions are built on very strong assumptions, this study presents our linear models.

\section{Analysis}

We first test whether the existing energy mix and the policy context are associated with individual preferences for renewable energy policies in general. As Table 1 demonstrates, there is no empirical support for the idea that a country's energy policy context affects its citizens' energy policy preferences.

Neither the share of fossil fuels in a country's electricity production, nor the existence of carbon pricing or a long tradition of energy supply regulations are statistically associated with individual policy preferences in our countries of interest. The share of renewables is a notable exception: the more electricity a country already produces from renewable energy sources, the more likely its citizens are to support a tax on fossil fuels. However, while in line with the positive feedback hypothesis (H2), this relationship is only of borderline statistical significance. ${ }^{11}$

\section{Table 1: The role of a country's energy mix and policy context on energy policy preferences}

\footnotetext{
${ }^{11}$ We also considered some control variables at the country level, such as GDP, EU membership, perceived corruption, and a dummy for Eastern European countries. We refrain from including these variables in the models for three reasons. Arguably, these control variables are important drivers of domestic energy policy, which results in considerable correlations and leads to multicollinearity. Relatedly, the energy policy variables arguably capture some of the economic, political, and institutional aspects, but at the same time, more directly and closely tackle our crucial theoretical arguments. In fact, there are no theoretical arguments about why the control variables should directly influence policy preferences, unless via the energy policy context. Thirdly, including these variables does not substantially affect our results and the interaction effects presented below, in particular.
} 


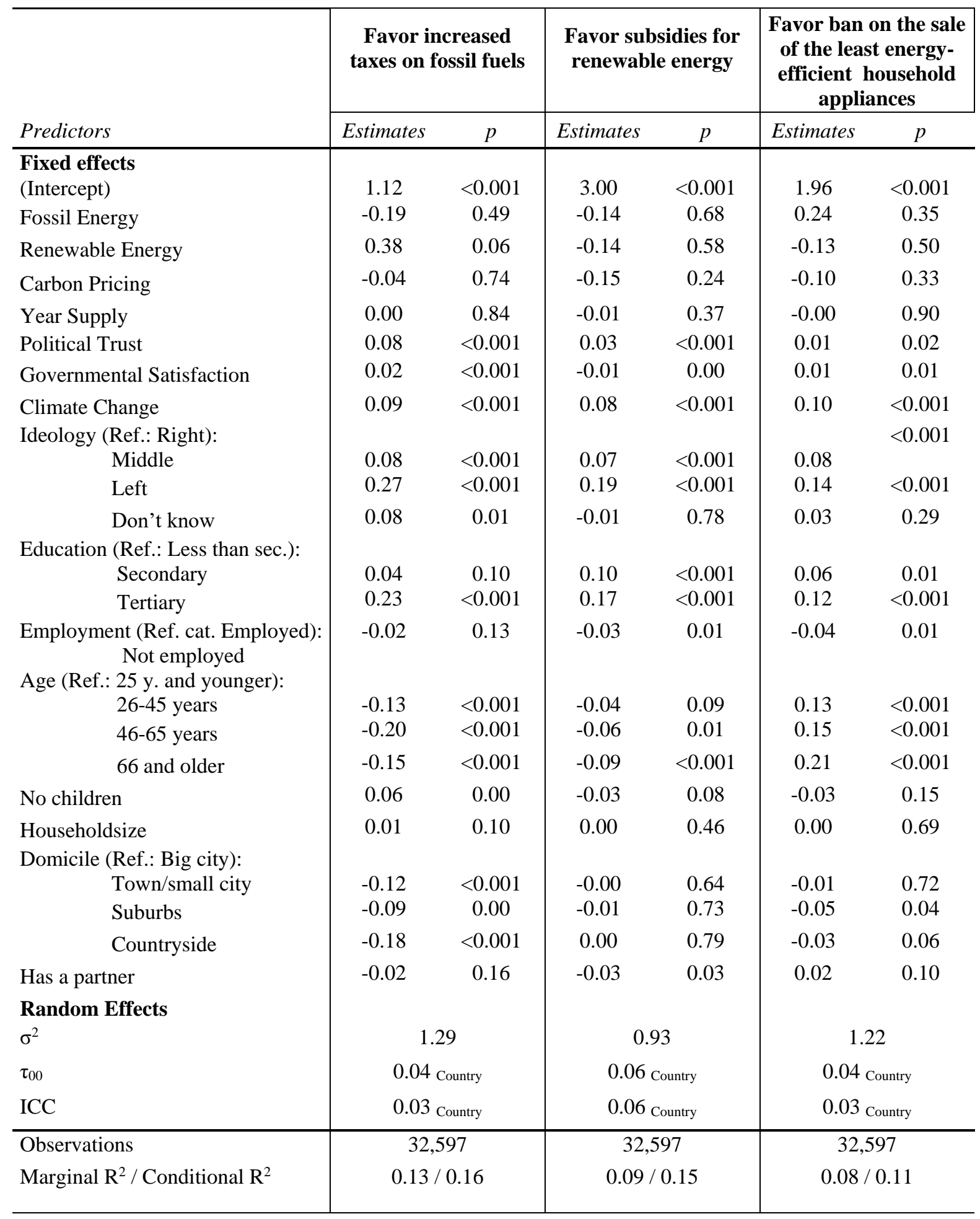

Note: Linear mixed-effects models calculated in R.

The results also demonstrate that individual attitudes strongly correlate with policy preferences: individuals with high political trust and satisfaction with their government are more likely to support any policy instrument. The same pattern holds true for climate change attitudes: The more individuals accept that anthropogenic climate change is happening; the more they support renewable energy policies. Moreover, and in keeping with earlier research (Drews and van den 
Bergh, 2015; Harring and Jagers, 2018; Ingold et al., 2018; Mayer and Smith, 2017), a leftist ideology, higher levels of education, an urban domicile, and young age are positively related to individual support for "green" policy instruments.

Theoretically, these results lend support to the view that the energy policy context in European countries is not visible and salient enough to noticeably affect people' attitudes, i.e., to create substantial feedback effects (but see Tosun and Mišić 2020). Moreover, at the time of the 2016 survey, other issues-migration, in particular-were much more prominent in the public discourse and made energy policy a rather neglected issue.

In a different vein, the likelihood of individual attitudes and characteristics being relevant to preferences for renewable energy policies steers our second empirical step, in which we test whether the link between the existing energy policy and individual policy preferences is moderated by individual attitudes. We proceed by expanding the models presented in Table 1 with interactions between the policy variables and individual attitudes like political trust and attitudes toward climate change. In an effort to prevent the model from being overloaded, we run two models for each dependent variable and for each individual-level variable: the first interacts individual attitudes with policy mix variables, while the second does so with policy context variables (see online appendix Tables A2 and A3 for the full results).

Figure 2 depicts the marginal effects of political trust at different levels of a country's share of fossil energy. The estimations for the three dependent variables generate a consistent and statistically significant ${ }^{12}$ pattern: individuals with higher levels of political trust are, on average, more likely to support energy policy instruments. Yet, the marginal effect of political trust on instrument support weakens as the share of fossil energy in the energy mix increases. Governments in countries with a strong fossil sector - a strong coal or oil industry - may find it harder to take measures that disadvantage this sector and/or strongly promote renewable energies (see Jacobsson and Lauber 2006: 269, Stokes 2013). Individuals with high levels of political trust seem to anticipate these considerations and to be less enthusiastic about "green" measures. Thus, these individuals back the energy path that is supported by the politicians they trust.

Germany seems to be an exception to this pattern: Although the country sports a strong coal sector, the German government has been one of the main and most prominent promoters of

\footnotetext{
${ }^{12}$ The interaction effect regarding the ban sale of least energy efficient household appliances is only significant at the $10 \%$ level. Given the low level of observations at level 2 this is still considerable.
} 
energy transition in recent years (Jacobsson and Lauber 2006). We therefore re-estimate the models excluding Germany (see documentation in the online appendix). In the new models, the interaction effects on individual support for tax increases and subsidies become even stronger. This corroborates our interpretation that governments in countries with strong fossil sectors are perceived to be (and probably are) more reluctant to adopt an "anti-fossil" policy (see e.g., Blondeel and Van de Graaf 2018), which is related to lower policy support from individuals who trust politicians' actions.

\section{Figure 2: Political trust, fossil energy, and energy policy preferences}
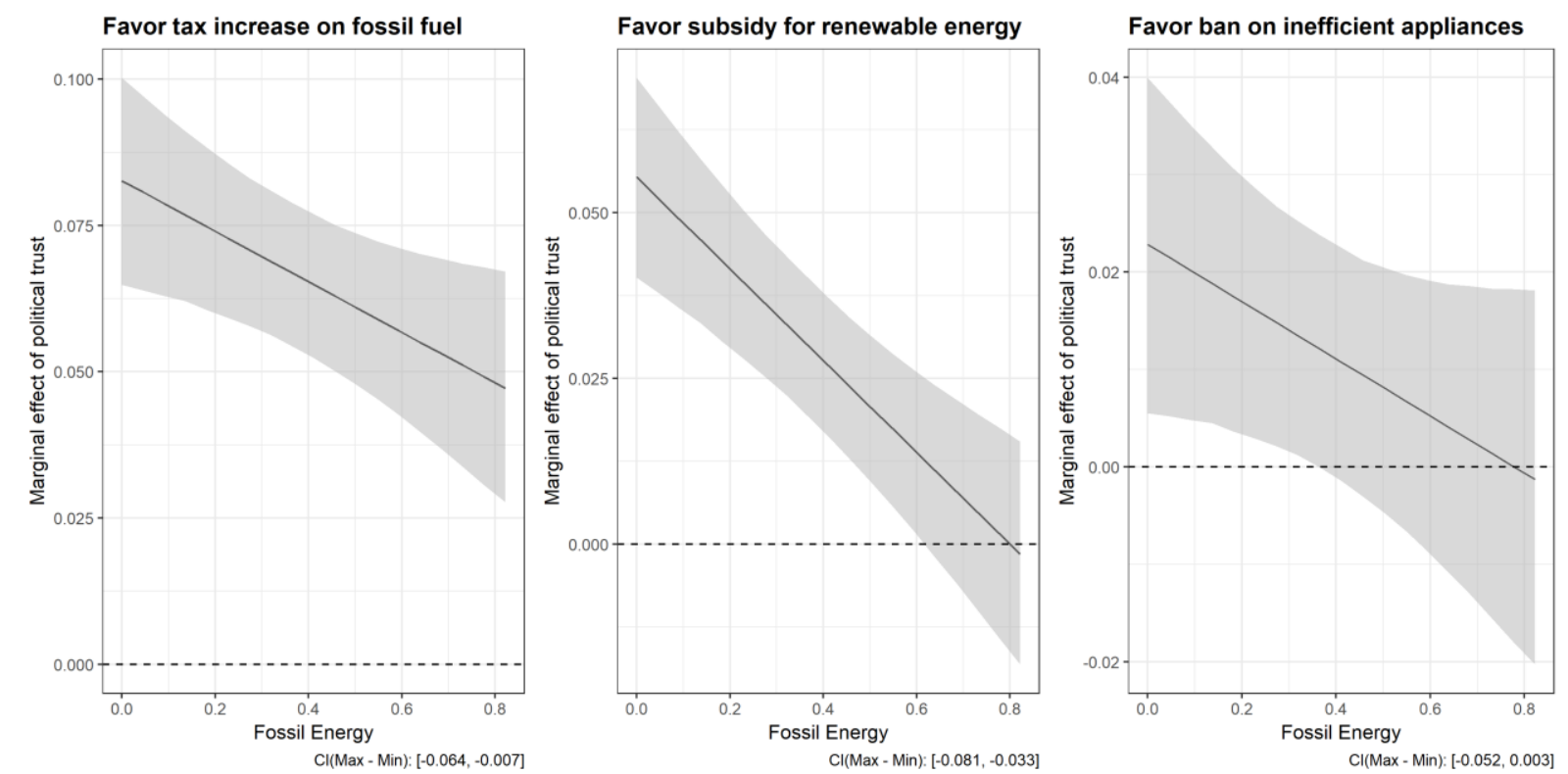

Note: Marginal effects plot (marginal effects and 95\%-interval) based on the interaction models presented in Table A. 2 in the online appendix.

Conversely, the interactions between political trust and each of the three other energy policy variables do not produce a similar significant and consistent pattern (for the full results, see online appendix Table A.2.) ${ }^{13}$. Hence, political trust's moderating effect suggests that the fossil energy sector in Europe produces a reinforcing positive feedback effect, which may serve as a hurdle to energy transition.

Furthermore, we also expect individuals attributing high importance and salience to climate change to react more strongly to the domestic energy policy context, i.e., be subject to a more noticeable positive feedback effect. Our models (for full results, see online appendix Table A.3.) clearly support this view. Eight out of nine interaction effects between such attitudes toward climate change and different aspects of a country's energy mix or energy policy tradition

\footnotetext{
${ }^{13}$ The exception is the interaction between trust and the «energy policy history» for which a similar pattern as reported in Figure 2 can be observed.
} 
are statistically significant. Carbon pricing is the only variable that does not produce a substantive interaction.

Figure 3 depicts the marginal effects of climate change attitudes in different energy contexts, whereby high values point to a clear acceptance of anthropogenic climate change. In the case of the share of renewable energy, Figure 3 (upper graphs) visualizes a clear message: while strong climate change attitudes go hand in hand with distinct preferences for renewable energy policies in general (and not surprisingly so), increasing renewable energy reinforces this relationship. The mechanism behind this moderating effect can be either normative or more pragmatic: normatively, a country's reliance on renewables may be rooted in a corresponding culture as well as in previous policies that attribute high salience to energy- and climate changerelated issues. Such contexts may encourage sensitized individuals in their pro-environmental policy preferences. A more pragmatic interpretation suggests that further pro-renewable policies are less costly in countries with high renewable energy shares: they would neither endanger important industries, nor induce substantial change. Individuals who think that climate change is relevant and human-made would therefore support any policy instrument that pushes for further energy transition.

\section{Figure 3: Climate change attitudes, energy mix, and energy policy preferences}
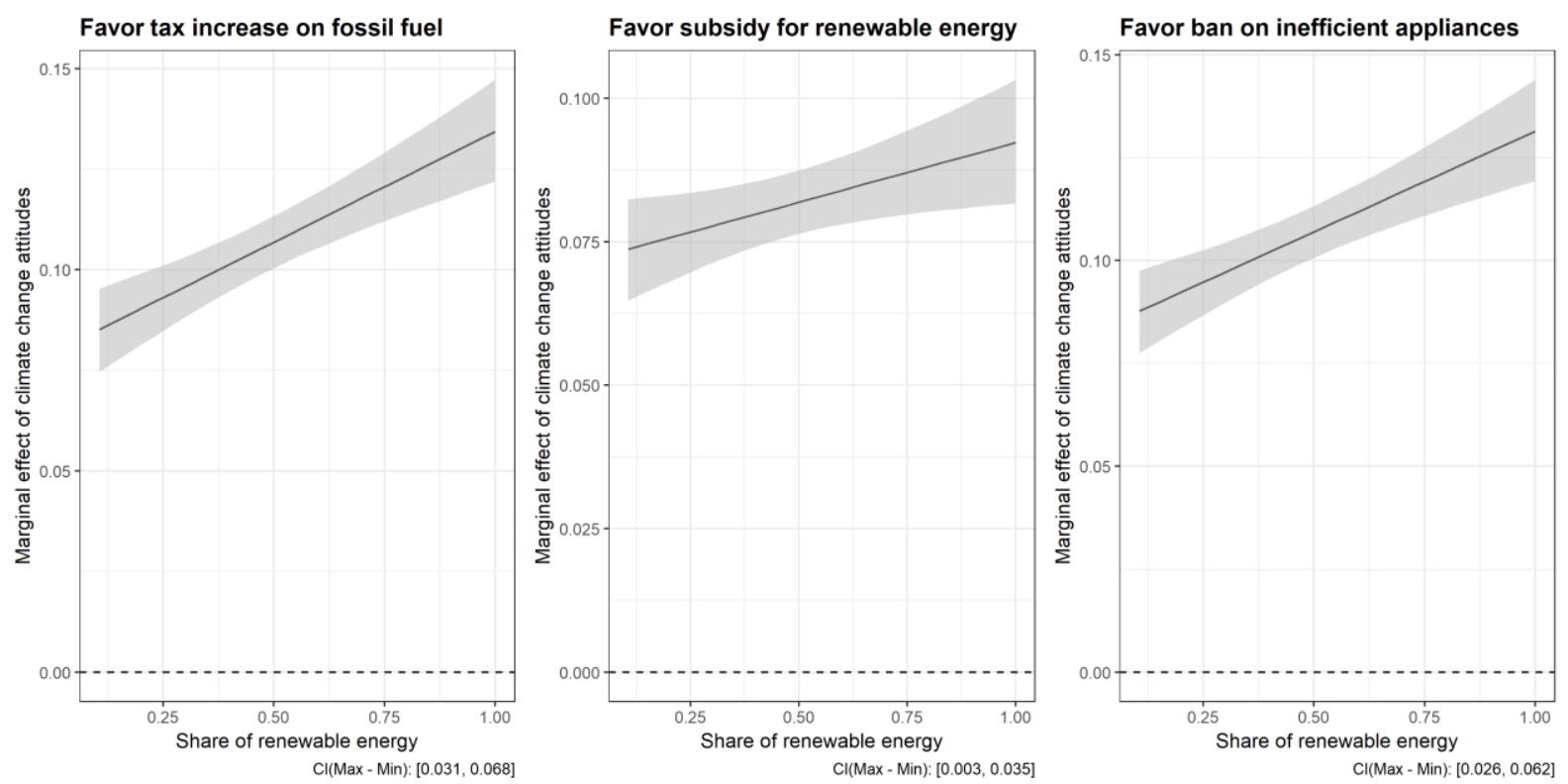

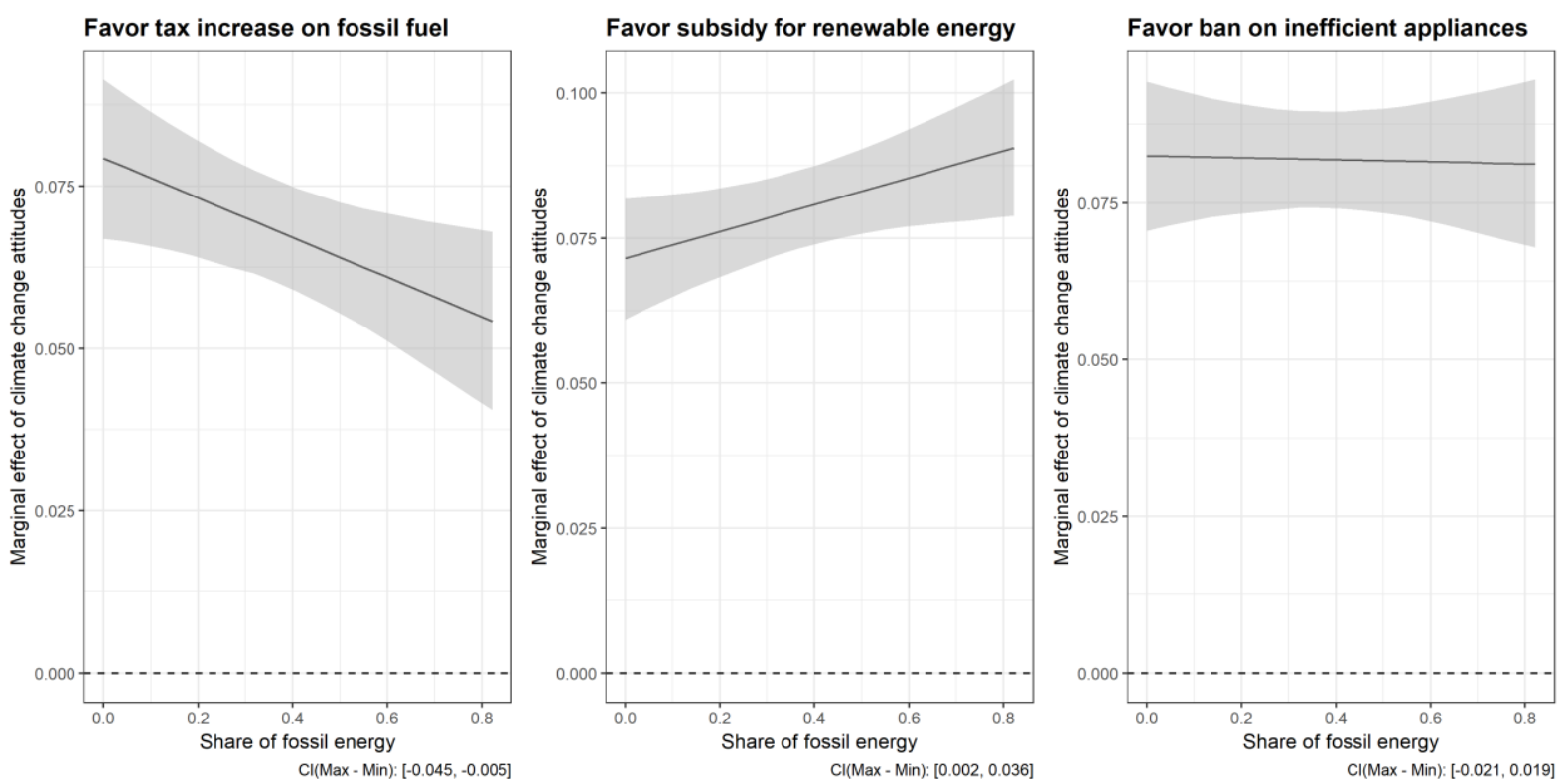

Note: Marginal effect plot (marginal effects and 95\%-interval) based on the interaction model presented in Table A.3 in the online appendix.

A somewhat different pattern emerges in Figure 4, which shows interactions with countries' energy policy tradition: the positive relationship between climate change attitudes and support for energy transition policies is weaker in those countries that have already introduced related policies some years ago.

Figure 4: Climate change attitudes, energy policy tradition, and energy policy preferences
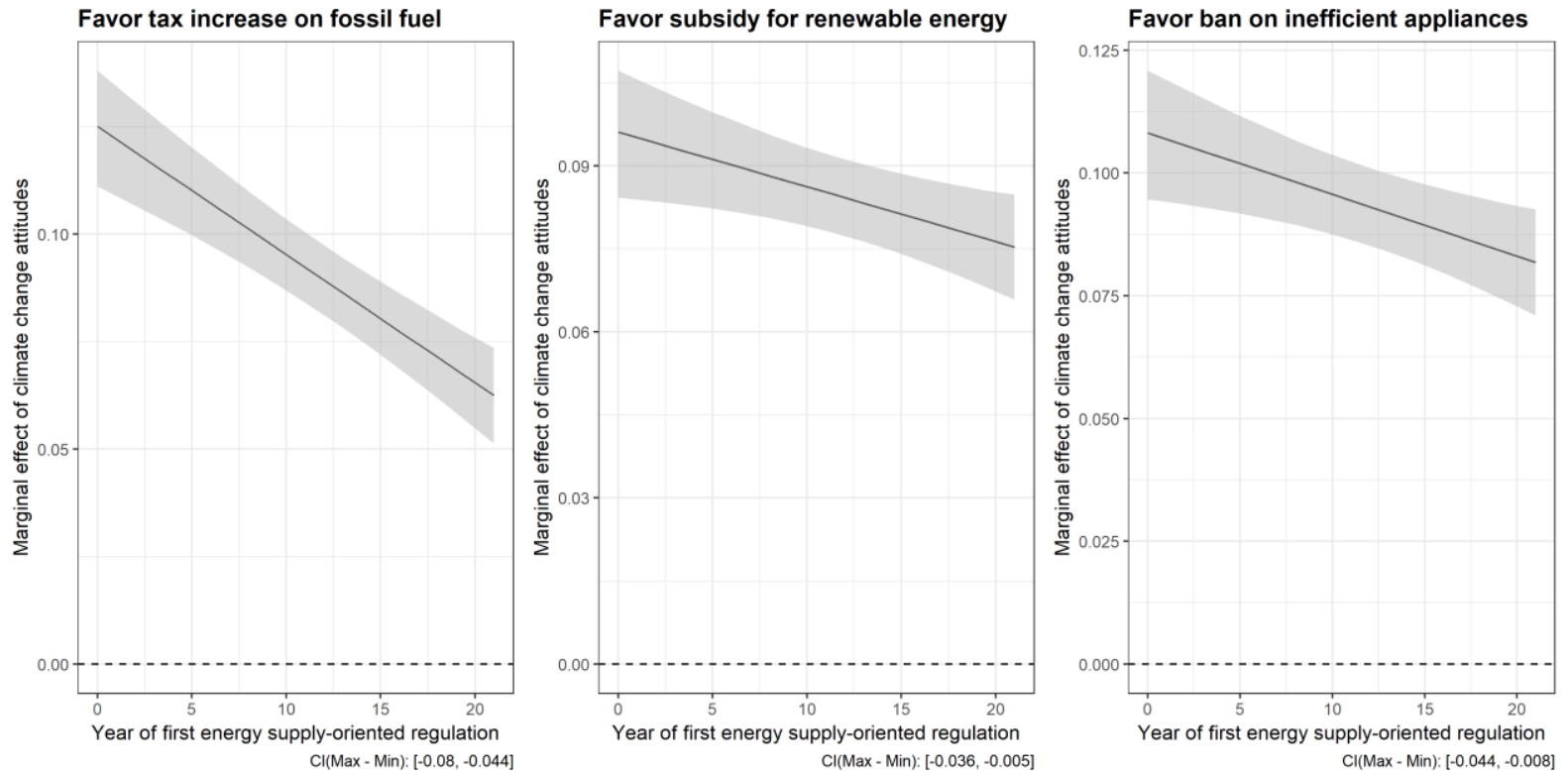

Note: Marginal effect plot (marginal effects and 95\%-interval) based on the interaction model presented in Table A.3 in the online appendix.

The picture seems to be slightly more complex when countries' fossil share of energy is interacted with climate change attitudes (Figure 3, lower graphs). In countries heavily relying 
on fossil energy, individuals with strong climate change attitudes are less supportive of tax increases than their counterparts in countries where the fossil energy share is lower. This finding fits an economic argument: where the fossil energy sector is important, higher taxes on fossil fuels may have negative economic effects, especially in countries' 'coal' regions. These potential hardships will be considered by individuals with manifest climate change-related attitudes and, thereby, will somewhat reduce the latter's support for this policy. In contrast, at the same shares of fossil energy, the same individuals seem to be particularly supportive of subsidies for renewable energies, which reflects a compensation mechanism: given their acknowledgement of the economic significance of the fossil sector, they find it even more important to promote renewables. Summarizing these results, we conclude that the current energy mix in a country is related to the policy mix individuals with strong climate change attitudes prefer. In contexts where fossil energy is not an economic factor, these individuals clearly support any policy promoting energy transition, while in "fossil countries," the tradeoff between economic costs and reaching environmental goals results in a preference for a particular policy mix.

The fact that the share of fossil energy does not moderate the association between climate change attitudes and the preference for a sale ban on least energy-efficient appliances seems reasonable, given that there is no obvious theoretical link between fossil energy and the energy efficiency of household appliances.

Overall, the analysis clearly supports the view that individual climate change attitudes and political trust strengthen the link between the domestic energy policy context and policy preferences, confirming the existence of a policy feedback.

\section{Discussion and conclusion}

In this paper, we have sought to investigate whether and how the existing energy policy context affects individual preferences for further renewable energy policies. Based on data from the $8^{\text {th }}$ round of the European Social Survey, we provide - to the best of our knowledge - one of the first comparative studies on these questions. Theoretically, we suggested a policy feedback approach and argued that individual attitudes, such as concern about climate change and political trust, affect how and to what extent individuals react to the energy policy context in which they live. The main findings of our analysis can be summarized as follows. 
Firstly, there is no systematic relationship between a country's energy policy context and citizens' preferences for instruments promoting renewable energy. This non-finding supports the existing argument that energy in general and energy policy in particular are not very visible and tangible to the broad public (cf. Brounen et al., 2013; Stadelmann-Steffen and Dermont, 2018). Electricity just comes out of the power plug and its cost for an average household is low enough for many people to not even know how much they pay for it each month. Therefore, the perspective of the policy feedback theory does not perceive energy policy as very proximate and visible to citizens and, accordingly, a substantial feedback effect is rather unlikely.

However, a second important finding of our study indicates that a country's energy policy context does produce feedback effects in some groups of the population. Focusing on climate change attitudes and political trust, our analysis revealed that individuals with strong climate change attitudes and high levels of political trust experience positive feedback effects. Theoretically, we argue that their attitudes strengthen the perceived visibility and proximity of energy policy, which also makes it more likely that contextual factors affect these individuals' policy preferences. Indeed, our results suggest that the existing energy policy context reinforces these groups' preferences for policies in line with the existing context. This is good news for those countries that already have a large share of renewable energy or have a long energy policy tradition: in these countries, individuals who accept that anthropogenic climate change is happening endorse any policy promoting renewable energy. This behavior lends support to the view that acknowledging anthropogenic climate change and the need to take measures against it is an important precondition for backing renewable energy and climate change mitigation policies (Ziegler, 2017: 144).

However, the feedback also has its downsides. In countries where the fossil energy sector still is a significant economic factor, even sensitized individuals are more reluctant to accept taxes on fossil fuel than their counterparts in other countries. Similarly, in these "fossil countries," individuals who strongly trust their politicians are particularly reluctant to support renewable energy policies. This disinclination can be interpreted to mean that citizens consider the current (fossil) energy mix as linked to current politics. Those who trust their politicians therefore tend to support the status quo. Thus, whereas a "renewable context" seems to have the potential to generate positive feedback in terms of at least causing sensitized citizens to demand more renewable energy, the very same feedback mechanism also explains why energy transition is so difficult to achieve in the first place, i.e., why countries often tend to under-react to the 
challenges of climate change (Peters et al. 2017), especially where fossil energy is an economic factor.

The last finding is very much in keeping with previous research on the key trade-offs of the energy transition: while renewable energy policy as such is broadly accepted and generally preferred to fossil energy sources, implementing policies to promote renewable energy typically involves visible costs (Dermont et al., 2017; Kirchgässner and Schneider, 2003) that also matter to individuals with strong pro-environmental or climate change-related values (StadelmannSteffen and Dermont, 2018). As Ziegler (2017: 152) puts it, “[E]ven when people believe in anthropogenic climate change, they do not automatically support policies for adaptation or mitigation activities or voluntarily conduct climate protection activities." Our analysis adds to these previous findings and demonstrates the merits of a policy mix approach: individuals with strong climate change attitudes living in "fossil countries" may pay particular attention to the trade-off between environmental and economic goals. Compared to their counterparts in "renewable energy countries," their policy preferences suggest that they try to solve this dilemma by carefully balancing between different policy instruments. While being somewhat less supportive of increasing taxes on fossil fuel, which reflects their economic concerns, they compensate this reluctance by openly supporting subsidies for renewable energy.

Our study is not without limits. Most importantly, we rely on individual preferences for varying policies measured in a survey context. This information can give us a good sense of countrydifferences in the socio-political acceptance of these policies (Wüstenhagen et al., 2007), but we should not expect these preferences to directly translate into corresponding real-world behavior. In fact, as with all analyses based on survey data and most especially when using unidimensional questions (see Stadelmann-Steffen and Dermont, 2018), we cannot rule out incorrect answers that are caused by misunderstandings, memory failure or social desirability bias. Nevertheless, our findings indicate that feedback loops exist in environmental politics as well. At a general level, our results suggest that public preferences not only matter on election day, but also when it comes to adopting and implementing energy policies. More specifically, the good news for policymakers is that renewable energy policies have the potential to reinforce themselves. However, this positive feedback is conditional on citizens' sensitization to climate change. Which, in turn, points to the bad news - current renewable energy policy in Europe is often not able to reach those social groups that are less sensitized to climate change. In this vein, the feedback mechanism we found involves a risk of greater polarization, where one group 
demands to further renewable energy policy, while others lag behind. Since reaching the Paris goals will only be possible if politicians and citizens work hand in hand, it is vital to gain the support of these groups. This could be achieved through adopting a variety of policies paired with increased educational efforts.

Funding: This project was partly financially supported by the Leibniz Association (Project “DominoES")

\section{References}

Aasen, Marianne and Arild Vatn (2018) Public attitudes toward climate policies: The effect of institutional contexts and political values. Ecological Economics 146: 106-114.

Blondeel, Mathieu, \& Thijs Van de Graaf (2018) Toward a global coal mining moratorium? A comparative analysis of coal mining policies in the USA, China, India and Australia. Climatic Change 150(1-2): 89-101.

Brounen, Dirk, Nils Kok and John M. Quigley (2013) Energy literacy, awareness, and conservation behavior of residential households. Energy Economics 38: 42-50.

Carattini, Stefano, Andrea Baranzini, Philippe Thalmann, Frédéric Varone and Frank Vöhringer (2017) Green taxes in a post-Paris world: Are millions of nays inevitable? Environmental and Resource Economics 68(1): 97-128.

Cherry, Todd L., Jorge H. García, Steffen Kallbekken and Asbjørn Torvanger (2014) The development and deployment of low-carbon energy technologies: The role of economic interests and cultural world views on public support. Energy Policy 68: 562-566.

Citrin, Jack and Laura Stoker (2018) Political trust in a cynical age. Annual Review of Political Science 21(1): 49-70.

Dermont, Clau (2018) Environmental decision-making: the influence of policy information. Environmental Politics online first: 1-24.

Dermont, Clau, Karin Ingold, Lorenz Kammermann and Isabelle Stadelmann-Steffen (2017) Bringing the policy making perspective in: A political science approach to social acceptance. Energy Policy 108: 359-368.

Drews, Stefan and Jeroen C. J. M. van den Bergh (2016) What explains public support for climate policies? A review of empirical and experimental studies. Climate Policy 16(7): 855-876.

Edenhofer, Ottmar, Ramón Pichs-Madruga, Youba Sokona, Kristin Seyboth, Patrick Matschoss, Susanne Kadner, Timm Zwickel, Patrick Eickemeier, Gerrit Hansen, Steffen 
Schloemer and Christoph von Stechow (2012) IPCC special report on renewable energy sources and climate change mitigation. Cambridge, Cambridge University Press.

Engels, Anita, Otto Hüther, Mike Schäfer and Hermann Held (2013) Public climate-change skepticism, energy preferences and political participation. Global Environmental Change 23(5): 1018-1027.

Firestone, Jeremy, Willett Kempton, Meredith Blaydes Lilley and Kateryna Samoteskul (2012) Public acceptance of offshore wind power across regions and through time. Journal of Environmental Planning and Management 55(10): 1369-1386.

Fredriksson, Per G. and Eric Neumayer (2016) Corruption and climate change policies: Do the bad old days matter? Environmental \& Resource Economics 63(2): 451-469.

Harring, Niklas (2014) Corruption, inequalities and the perceived effectiveness of economic pro-environmental policy instruments: A European cross-national study. Environmental Science \& Policy 39: 119-128.

Harring, Niklas and Sverker C. Jagers (2013) Should we trust in values? Explaining public support for pro-environmental taxes. Sustainability 5(1): 210-227.

Harring, Niklas and Sverker C. Jagers (2018) Why do people accept environmental policies? The prospects of higher education and changes in norms, beliefs and policy preferences. Environmental Education Research 24(6): 791-806.

Hetherington, Marc J. (2014) The political relevance of political trust. American Political Science Review 92(4): 791-808.

Ingold, Karin, Isabelle Stadelmann-Steffen and Lorenz Kammermann (2018) The acceptance of instruments in instrument mix situations: Citizens' perspective on Swiss energy transition. Research Policy (forthcoming).

Jacobsson, Staffan and Volkmar Lauber (2006) The politics and policy of energy system transformation - Explaining the German diffusion of renewable energy technology. Energy Policy 34(3): 256-276.

Jagers, Sverker C., Niklas Harring and Simon Matti (2018) Environmental management from left to right - on ideology, policy-specific beliefs and pro-environmental policy support. Journal of Environmental Planning and Management 61(1): 86-104.

Kirchgässner, Gebhard and Friedrich Schneider (2003) On the political economy of environmental policy. Public Choice 115(3): 369-396.

Kumlin, Staffan and Isabelle Stadelmann-Steffen (Eds.) (2014). How Welfare States Shape the Democratic Public: Policy Feedback, Participation, Voting and Attitudes. Cheltenham, Edward Elgar Publishing Limited. 
Le Quéré, Corinne, Jan Ivar Korsbakken, Charlie Wilson, Jale Tosun, Robbie Andrew, Robert J. Andres, Josep G. Canadell, Andrew Jordan, Glen P. Peters and Detlef P. van Vuuren (2019) Drivers of declining CO2 emissions in 18 developed economies. Nature Climate Change 9(3): 213-217.

Lowry, William R. and Mark Joslyn (2014) The determinants of salience of energy issues. Review of Policy Research 31(3): 153-172.

Mayer, Adam and E. Keith Smith (2017) Education, political affiliation and energy policy in the United States: A case of Tea Party exceptionalism? Energy Research \& Social Science 23(1): 74-81.

McCright, Aaron M., Riley E. Dunlap and Sandra T. Marquart-Pyatt (2016) Political ideology and views about climate change in the European Union. Environmental Politics 25(2): 338-358.

Peters, B. Guy., Andrew Jordan, and Jale Tosun (2017) Over-reaction and under-reaction in climate policy: An institutional analysis. Journal of Environmental Policy \& Planning, 19(6): 612624.

Pierson, Paul (2011) The new politics of the welfare state. World Politics 48(2): 143-179.

Schmidt, Nicole M. and Andreas Fleig (2018) Global patterns of national climate policies: Analyzing 171 country portfolios on climate policy integration. Environmental Science \& Policy 84: 177-185.

Shwom, Rachael, David Bidwell, Amy Dan and Thomas Dietz (2010) Understanding U.S. public support for domestic climate change policies. Global Environmental Change 20(3): 472-482.

Skocpol, Theda (1992) Protecting soldiers and mothers: The political origins of social policy in the United States. Cambridge, Harvard University Press.

Soroka, Stuart N. and Christopher Wlezien (2009) Degrees of democracy: Politics, public opinion, and policy. Cambridge, Cambridge University Press.

Soss, J. O. E. and Sanford F. Schram (2007) A public transformed? Welfare reform as policy feedback. American Political Science Review 101(1): 111-127.

Stadelmann-Steffen, Isabelle (2019) Bad news is bad news: Information effects and citizens' socio-political acceptance of new technologies of electricity transmission. Land Use Policy 81: 531-545.

Stadelmann-Steffen, Isabelle and Clau Dermont (2018) The unpopularity of incentive-based instruments: what improves the cost-benefit ratio? Public Choice 175(1): 37-62. 
Stokes, Leah C. (2013) The politics of renewable energy policies: The case of feed-in tariffs in Ontario, Canada. Energy Policy 56: 490-500.

Tosun, Jale (2018) Investigating ministry names for comparative policy analysis: Lessons from energy governance. Journal of Comparative Policy Analysis: Research and Practice 20(3): 324-335.

Tosun, Jale and Misic, Mile (2020). "Conferring Authority in the European Union: Citizens' Policy Priorities for the European Energy Union.” Journal of European Integration, 42(1), forthcoming.

Wlezien, Christopher (1995) The public as a thermostat: Dynamics of preferences for spending. American Journal of Political Science 39(4): 981-1000.

Wlezien, Christopher and Stuart N. Soroka (2016) Public opinion and public policy. Oxford, Oxford University Press.

Wolsko, Christopher, Hector Ariceaga and Jesse Seiden (2016) Red, white, and blue enough to be green: Effects of moral framing on climate change attitudes and conservation behaviors. Journal of Experimental Social Psychology 65(1): 7-19.

Wüstenhagen, Rolf, Maarten Wolsink and Mary Jean Bürer (2007) Social acceptance of renewable energy innovation: An introduction to the concept. Energy Policy 35(5): 26832691.

Ziegler, Andreas (2017) Political orientation, environmental values, and climate change beliefs and attitudes: An empirical cross-country analysis. Energy Economics 63: 144-153. 